\title{
Isoeugenin, a Novel Nitric Oxide Synthase Inhibitor Isolated from the Rhizomes of Imperata cylindrica
}

\author{
Hyo-Jin An ${ }^{1}$, Agung Nugroho ${ }^{2}$, Byong-Min Song ${ }^{3}$ and Hee-Juhn Park ${ }^{4, *}$ \\ Received: 28 October 2015 ; Accepted: 24 November 2015 ; Published: 1 December 2015 \\ Academic Editors: Derek J. McPhee and John A. Beutler \\ 1 Department of Pharmacology, College of Korean Medicine, Sangji University, Wonju 220-702, Korea; \\ hjan@sj.ac.kr \\ 2 Department of Agro-Industrial Technology, Faculty of Agriculture, Lambung Mangkurat University, \\ Indonesia 70712, Indonesia; agung_tin@yahoo.com \\ 3 Department of Forest Science, College of Life Science and Natural Resources, Sangji University, \\ Wonju 220-702, Korea; bmsong@sangji.ac.kr \\ 4 Department of Pharmaceutical Engineering, College of Health Science, Sangji University, \\ Wonju 220-702, Korea \\ * Correspondence: hjpark@sangji.ac.kr; Tel.: +82-33-730-0564
}

\begin{abstract}
Phytochemical studies on the constituents of the rhizomes of Imperata cylindrica (Gramineae) were performed using high-performance liquid chromatography (HPLC). We also aimed to search for any biologically active substance capable of inhibiting nitric oxide (NO) formation in lipopolysaccharide (LPS)-activated macrophage 264.7 cells, by testing four compounds isolated from this plant. Four compounds, including a new chromone, isoeugenin, along with ferulic acid, $p$-coumaric acid, and caffeic acid were isolated and identified by NMR spectroscopy. The structure of isoeugenin was determined as 7-hydroxy-5-methoxy-2-methylchromone by the 2D-NMR technique. Among the four compounds, isoeugenin has the lowest $\mathrm{IC}_{50}$ value on the inhibition of NO production in LPS-activated macrophage RAW264.7 cells $\left(\mathrm{IC}_{50}, 9.33 \mu \mathrm{g} / \mathrm{mL}\right)$. In addition, isoeugenin significantly suppressed the LPS-induced expressions of inducible nitric oxide synthase (iNOS), cyclooxygenase-2 (COX-2), and proinflammatory cytokines mRNA levels. Taken together, these results suggest that the anti-inflammatory activity of isoeugenin is associated with the down-regulation of iNOS, COX-2, and pro-inflammatory cytokines in RAW264.7 cells. Accordingly, our results suggest that the new chromone isoegenin should be considered a potential treatment for inflammatory disease.
\end{abstract}

Keywords: Imperata cylindrica; isoeugenin; RAW264.7 macrophages; NO; HPLC

\section{Introduction}

Imperata cylindrica, also called cogongrass, a traditional medicinal plant in Asia, is a widespread grass and is among the top 10 worst invasive weeds in the world. Traditionally, I. cylindrica is an Asian herb used to stop bleeding, as an expectorant, and as an anti-fever and anti-inflammatory agent. Recently, several compounds isolated from cogongrass exhibited medicinal properties, including anticancer properties, platelet aggregation inhibition, and hepatoprotective activities [1].

The major phytochemical constituents identified in I. cylindrica are phenylpropanoids [2], lignan glycosides [3], biphenyl ethers [4], sesquiterpenoids [5], phenolic compounds [6], lignans [5], and megastigmatrienone [7].

Several biologically active substances have been also reported to be present in I.cylindrica. These include the 5-lipoxygenase inhibitor cylindol A, vasodilator cylindrene, platelet aggregation inhibitor imperanene, and neuroprotectives 5-hydroxy-2(2-phenylethyl) chromone 
and 5-hydroxy-2(2-(2-hydroxyphenyl)ethyl) chromone. However, anti-inflammatory effect of I. cylindrica and its components have not been investigated.

Inflammation is a response to injury caused by physical or chemical noxious stimuli or microbiological toxins, and occurs in multiple pathologies, such as, arthritis, asthma, multiple sclerosis, inflammatory bowel diseases, and atherosclerosis [8]. In the inflammatory state, activated immune cells, such as macrophages secrete large amounts of proinflammatory cytokines and nitric oxide (NO). High levels of proinflammatory cytokines and NO in chronic inflammatory states can result in various pathological conditions [9]. In macrophages, lipopolysaccharide (LPS), a well-known endotoxin, induces the production of the inflammatory cytokines such as tumor necrosis factor- $\alpha$ (TNF- $\alpha$ ), interleukin (IL)- 6 , and IL-1 $\beta$, as well as inflammatory mediators, including $\mathrm{NO}$ and prostaglandin $\mathrm{E}_{2}\left(\mathrm{PGE}_{2}\right)$, that are synthesized by inducible $\mathrm{NO}$ synthase (iNOS) and cyclooxygenase-2 (COX-2), respectively $[8,10]$.

Accordingly, control of the production of proinflammatory cytokines and $\mathrm{NO}$ in macrophages are current research topics for the development of new anti-inflammatory agents. As a part of our on-going screening project to evaluate the anti-inflammatory potentials of natural compounds, we isolated four compounds from the rhizomes of I. cylindrica and investigated their anti-inflammatory effects on LPS-stimulated RAW264.7 macrophages.

\section{Results and Discussion}

\subsection{Isolation and Characterization of Compounds}

The $\mathrm{CHCl}_{3}$ fraction fractionated from the $\mathrm{MeOH}$ extract of I. cylindrica was subjected to column chromatography to afford four compounds. The ${ }^{1} \mathrm{H}-\mathrm{NMR}$ spectrum of compound $\mathbf{1}$ measured in DMSO- $d_{6}$ exhibited a vinylic methyl signal at $\delta 2.52$. A singlet peak of $\mathrm{H}-3$ at $\delta 5.60$, the two doublet peaks of $\mathrm{H}-6$ and 8 appearing as meta-coupled peaks $(J=1.8 \mathrm{~Hz})$, together with a peak attributed to a $\mathrm{OCH}_{3}$ group at $\delta 3.93(3 \mathrm{H}, \mathrm{s})$ suggests that compound $\mathbf{1}$ belongs to the chromone-type family of compounds.

The representative chromone-type compounds include eugenin, noreugenin, eugenitin, isoeugenitin, and isoeugenitol [11]. All of these have two $\mathrm{CH}_{3}$ groups, but some of them do not have a $\mathrm{OCH}_{3}$. The HR-ESI-MS showed that compound 1 exhibited an $\mathrm{m} / \mathrm{z}$ of 206.0579 corresponding to a $\left[\mathrm{C}_{11} \mathrm{H}_{10} \mathrm{O}_{4}\right]^{+}$molecular ion. Although the molecular formula of compound $\mathbf{1}$ is the same as that of eugenin, its NMR data was different from other chromone-type compounds, therefore, compound $\mathbf{1}$ is different from known chromone-type compounds. In particular, the literature [11] indicates that eugenin possessing a 5-OH exhibits a peak of $\delta_{\mathrm{C}} 182.7$ (in $\mathrm{CDCl}_{3}$ ); therefore, it is suggested that compound 1 has a $5-\mathrm{OCH}_{3}$ instead of a 5-OH according to its $\delta 169.9$ value (in DMSO).

The peak at $\delta 2.52(3 \mathrm{H}, \mathrm{s})$ is attributable to $2-\mathrm{CH}_{3}$, commonly observed in this type of compounds [12] because the heteronuclear multiple-bond correlation spectroscopy (HMBC) spectrum showed its long-range coupling with $\delta_{C} 138.7,87.2$, and 169.9 as shown in Figure 1. A singlet peak $\left(\delta_{\mathrm{H}} 5.60\right)$ attributable to $\mathrm{H}-3$ overlapped with the peak at $\delta_{\mathrm{C}} 169.9$ of carbonyl. The position of $5-\mathrm{OCH}_{3}$ assignable to $\delta_{\mathrm{H}} 3.93$ can be determined since the $\mathrm{OCH}_{3}$ peak is correlated with $\delta_{C} 169.9$ (C-4). Therefore, the structure of compound $\mathbf{1}$ was determined as 7-hydroxy-5-methoxy-2-methyl-chromone, called isoeugenin. Compounds $\mathbf{2 - 4}$ were identified as ferulic acid [13], $p$-coumaric acid [14], and caffeic acid [15], respectively, after comparing our ${ }^{1} \mathrm{H}$ and ${ }^{13} \mathrm{C}-\mathrm{NMR}$ data with the literature data. Furthermore, Compounds $\mathbf{2}-\mathbf{4}$ were identical to each corresponding standard compound on thin layer chromatography (TLC) and high performance liquid chromatography (HPLC).

The four phenolic substances were analyzed using HPLC, and the chromatograms are shown in Figure 2. Regression equations were established as shown in Table 1, by estimating peak areas measured at six concentrations $(12,5,25,50,100,200$, and $1000 \mu \mathrm{g} / \mathrm{mL})$. Each equation was verified for linearity at $R^{2}>0.999$. 


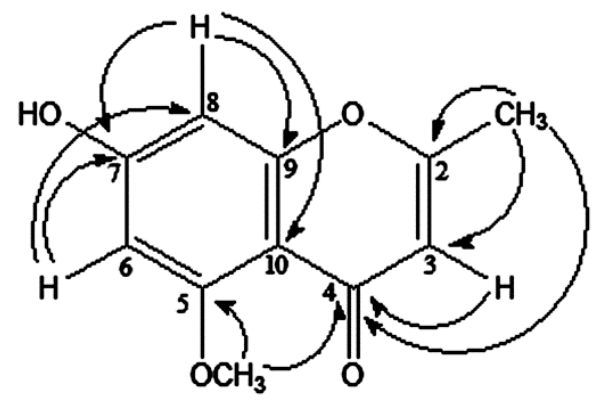

Figure 1. Structure of isoeugenin (1) isolated from I. cylindrica var. major and heteronuclear multiple-bond correlation spectroscopy (HMBC) correlation.

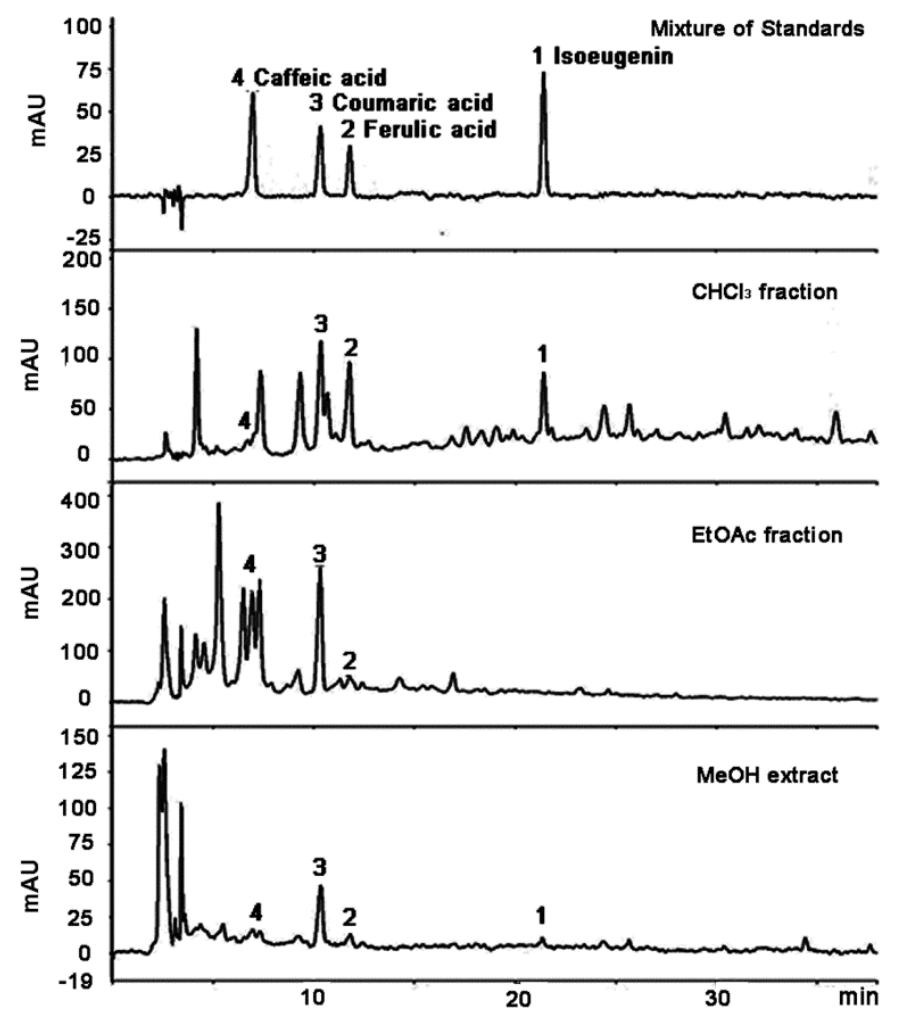

Figure 2. HPLC chromatograms of the MeOH extract of I. cylindrica and its fractions.

Table 1. Linearity of standard curves and detection/quantification limits for the standard compounds.

\begin{tabular}{ccccccc}
\hline $\begin{array}{c}\text { Standard } \\
\text { Compounds }\end{array}$ & $\boldsymbol{t}_{R}(\mathbf{m i n})$ & $\begin{array}{c}\text { Calibration Equation } \\
(\text { Linear Model) }\end{array}$ & $\begin{array}{c}\text { Linear Range } \\
(\mu \mathbf{g} / \mathbf{m L})\end{array}$ & $\mathbf{R}^{\mathbf{2} \mathbf{b}}$ & $\begin{array}{c}\mathbf{L O D}^{\mathbf{c}} \\
(\mu \mathbf{g} / \mathbf{m L})\end{array}$ & $\begin{array}{c}\mathbf{L O Q}^{\mathbf{d}} \\
(\mu \mathbf{g} / \mathbf{m L})\end{array}$ \\
\hline Caffeic acid & 6.92 & $y=747.05 x+83.33$ & $12.50-200.0$ & 0.9998 & 0.16 & 0.52 \\
-Coumaric acid & 10.30 & $y=245.73 x+95.83$ & $12.50-200.0$ & 0.9998 & 0.42 & 1.41 \\
Ferulic acid & 11.75 & $y=276.37 x+41.66$ & $12.50-200.0$ & 0.9993 & 0.57 & 1.91 \\
Isoeugenin & 21.42 & $y=40.468 x+30.26$ & $25.00-1000.0$ & 0.9998 & 4.19 & 13.97 \\
\hline
\end{tabular}

a $y$, peak area at $254 \mathrm{~nm} ; x$, concentration of the standard $(\mu \mathrm{g} / \mathrm{mL}) ;{ }^{b} \mathrm{R}^{2}$, correlation coefficient for 5 data points in the calibration curves $(n=4) ;{ }^{\mathrm{c}} \mathrm{LOD}$, limit of detection $(\mathrm{S} / \mathrm{N}=3) ;{ }^{\mathrm{d}} \mathrm{LOQ}$, limit of quantification $(\mathrm{S} / \mathrm{N}=10)$.

The contents of the four compounds were evaluated and revealed to be in the following order of abundance: isoeugenin (approximately $0.268 \mathrm{mg} / \mathrm{g}$ dry weight) $>$ ferulic acid (approximately $0.042 \mathrm{mg} / \mathrm{g}$ ) > p-coumaric acid (approximately $0.182 \mathrm{mg} / \mathrm{g}$ ) > caffeic acid (approximately $0.020 \mathrm{mg} / \mathrm{g}$ ). These four compounds were distributed mainly in the $\mathrm{CHCl}_{3}$ and EtOAc fractions 
as shown in Table 2. However, these substances are present in minute quantities in the hexane and $\mathrm{BuOH}$ fractions and isoeugenin was not detected in the EtOAc fraction.

Table 2. Content of analytes in the extract and fractions of I. cylidrica.

\begin{tabular}{ccccc}
\hline \multirow{2}{*}{ Analyte } & \multicolumn{2}{c}{ MeOH Extract } & \multicolumn{2}{c}{ Fractions $\mathbf{~ ( m g / g ~ E x t r a c t ) ~}$} \\
\cline { 2 - 5 } & $\mathbf{( m g / g}$ Dry Weight) & $\mathbf{( m g / g}$ Extract) & $\mathbf{C H C l}_{\mathbf{3}}$ & EtOAc \\
\hline Caffeic acid & 0.020 & 0.15 & 0.32 & 4.59 \\
$p$-Coumaric acid & 0.182 & 1.32 & 3.73 & 16.18 \\
Ferulic acid & 0.042 & 0.30 & 4.89 & 2.97 \\
Isoeugenin & 0.268 & 1.94 & 28.09 & n.d. \\
Total & 0.512 & 3.71 & 37.03 & 23.74 \\
\hline
\end{tabular}

\subsection{Inhibitory Effect of Compounds on LPS-Induced NO Production}

When the cytotoxicity of the $\mathrm{MeOH}$ extract and its fractions were evaluated in macrophage 264.7 cells, only the $\mathrm{CHCl}_{3}$ fraction exhibited cytotoxicity at more than $100 \mu \mathrm{g} / \mathrm{mL}$. The $\mathrm{MeOH}$ extract and other fractions displayed almost no cytotoxicity below $100 \mu \mathrm{g} / \mathrm{mL}$ concentration. When the cytotoxicity of the isolated compounds was evaluated in the cells, isoeugenin has a little cytotoxicity at $100 \mu \mathrm{g} / \mathrm{mL}$ and no cytotoxicity below $50 \mu \mathrm{g} / \mathrm{mL}$. Ferulic acid, coumaric acid, and caffeic acid have no cytotoxicity at $12.5,25$, and $50 \mu \mathrm{g} / \mathrm{mL}$ (data not shown).

The inhibitory effects of the isolated compounds on NO formation in the LPS-activated macrophage 264.7 cells are shown in Table 3. In this experiment, concentrations less than those showing cytotoxicity were chosen for the nitrite assay. Isoeugenin considerably reduced NO formation in LPS-activated cells, although other compounds exhibited very low activities. The $\mathrm{IC}_{50}$ value of isoeugenin on the inhibition of $\mathrm{NO}$ formation was $9.33 \mu \mathrm{g} / \mathrm{mL}$.

Table 3. Inhibitory effect of components of I. cylidrica on the LPS-induced NO production.

\begin{tabular}{cccc}
\hline Group & Concentration & NO Production $(\mu \mathbf{M})$ & Inhibition (\%) \\
\hline NOR & - & $11.90 \pm 0.65$ & - \\
LPS & - & $77.18 \pm 0.82^{\#}$ & - \\
L-NIL $(\mu \mathrm{M})$ & 20 & $36.12 \pm 1.56^{* * *}$ & $53.21 \pm 2.02$ \\
\hline \multirow{2}{*}{ Isoeugenin $(\mu \mathrm{g} / \mathrm{mL})$} & 12.5 & $32.96 \pm 0.47^{* * *}$ & $57.29 \pm 0.61$ \\
& 25 & $10.36 \pm 0.16^{* * *}$ & $86.58 \pm 0.20$ \\
& 50 & $6.12 \pm 0.16^{* * *}$ & $92.07 \pm 0.20$ \\
\hline \multirow{2}{*}{ Ferulic Acid $(\mu \mathrm{g} / \mathrm{mL})$} & 25 & $79.05 \pm 3.08$ & $-2.42 \pm 3.99$ \\
& 50 & $79.67 \pm 3.16$ & $-3.22 \pm 4.09$ \\
Coumaric acid $(\mu \mathrm{g} / \mathrm{mL})$ & 100 & $72.56 \pm 0.71^{* *}$ & $5.99 \pm 0.91$ \\
& 25 & $77.89 \pm 1.49$ & $-0.92 \pm 1.92$ \\
Caffeic acid $(\mu \mathrm{g} / \mathrm{mL})$ & 50 & $77.00 \pm 2.46$ & $0.23 \pm 3.19$ \\
& 100 & $72.83 \pm 1.67 * *$ & $5.64 \pm 2.16$ \\
\hline & 25 & $76.38 \pm 1.49$ & $1.04 \pm 1.06$ \\
& 50 & $74.87 \pm 0.67$ & $2.99 \pm 0.87$ \\
\hline
\end{tabular}

Cells were pretreated with different concentrations $(12.5,25,50,100 \mu \mathrm{g} / \mathrm{mL})$ of samples for $1 \mathrm{~h}$, then with LPS $(1 \mu \mathrm{g} / \mathrm{mL}$ ), and incubated for $24 \mathrm{~h}$. Normal (NOR) values were obtained in the absence of LPS and samples. L-NIL was used as a positive control at a concentration of $20 \mu \mathrm{M} .{ }^{\#} p<0.05 v \mathrm{~s}$. the normal controls; ${ }^{* *} p<0.01$; ${ }^{* *} p<0.001 \mathrm{vs} .1 \mu \mathrm{g} / \mathrm{mL}$ LPS-treated cells; the significances of differences between treated groups were determined using ANOVA and Dunnett's post hoc test.

\subsection{Inhibitory Effect of Isoeugenin on the LPS-Induced iNOS and COX-2 Expressions}

To determine whether the inhibitory effects of isoeugenin on NO productions are related to the modulation of iNOS and COX-2 enzymes, we examined their expression levels by western blotting. In unstimulated RAW264.7 cells, iNOS and COX-2 protein levels were undetectable. 
However, in response to LPS, the expression levels of iNOS and COX-2 were markedly upregulated, and isoeugenin significantly inhibited the LPS-stimulated iNOS and COX-2 expressions in a dose-dependent manner (Figure 3).

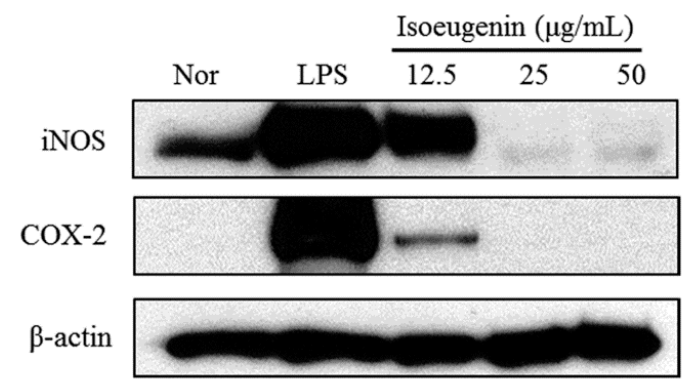

Figure 3. Inhibitory effects of isoeugenin on LPS-induced iNOS and COX-2 protein expressions in RAW264.7 cells. Cells were pretreated with different concentrations $(12.5,25,50 \mu \mathrm{g} / \mathrm{mL})$ of isoeugenin for $1 \mathrm{~h}$, then with LPS $(1 \mu \mathrm{g} / \mathrm{mL})$, and incubated for $24 \mathrm{~h}$. Total cellular proteins ( $30 \mu \mathrm{g})$ were resolved by SDS-PAGE, transferred to nitrocellulose membranes, and detected with specific antibodies, as described in the Experimental Section. NOR values were obtained in the absence of LPS and samples. LPS values were obtained in only LPS treatment. A representative immunoblot of three separate experiments is shown.

\subsection{Inhibitory Effect of Isoeugenin on the LPS-Induced mRNA Levels of Cytokines}

To evaluate the effect of isoeugenin on the pro-inflammatory cytokines, we further examined the expressions of TNF- $\alpha$, IL- 6 , and IL- $1 \beta$ in LPS-stimulated macrophages pretreated with isoeugenin by quantitative Real-time PCR. Pretreatment with isoeugenin was found to reduce LPS-induced TNF- $\alpha$, IL-6, and IL-1 $\beta$ mRNA expressions in a concentration-dependent manner (Figure 4). These three cytokines are known to act as pro-inflammatory mediators in vitro and in vivo. TNF- $\alpha$ exhibits its pro-inflammatory activity by regulating several intercellular and vascular cell adhesion molecules, which results in the recruitment of leukocytes to sites of inflammation [16]. IL-6 is a cytokine released by LPS-activated monocytes and plays a crucial role in immune response [17]. For example, the overexpression of IL-6 is involved in pathological conditions, such as, rheumatoid arthritis [18]. IL-1 $\beta$ is normally produced in response to infection, injury, or immunologic challenge; at minimal concentrations, it causes fever, hypotension, and production of additional proinflammatory cytokines, such as IL-6 [19]. Collectively, isoeugenin has the potential for inhibition not only iNOS and COX-2 expression but also a wide range of the pro-inflammatory genes regulated.

A

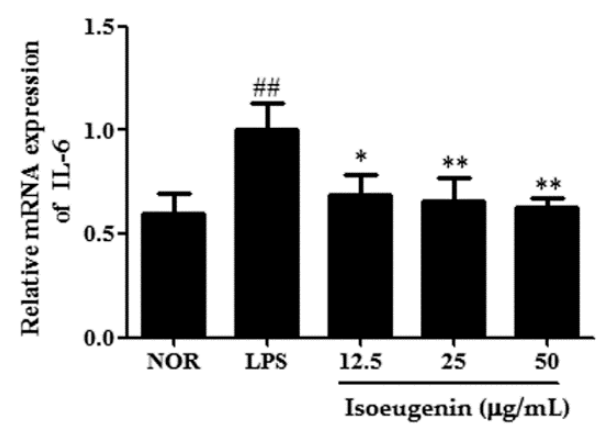

B

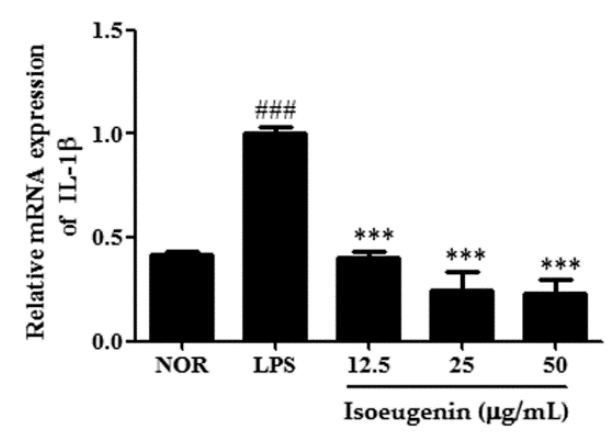

Figure 4. Cont. 


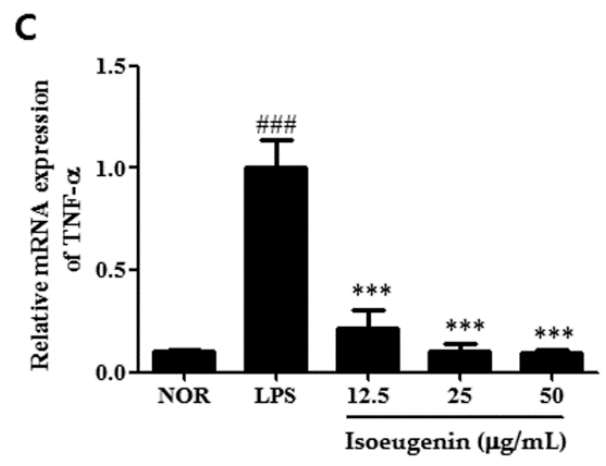

Figure 4. Inhibitory effect of isoeugenin on LPS-induced TNF- $\alpha$ (A); IL-6 (B); IL-1 $\beta$ (C) mRNA expression in RAW264.7 cells. Total RNA was prepared for the Real Time-PCR analysis of TNF- $\alpha$, IL-6, IL-1 $\beta$ gene expression from RAW264.7 macrophage cells pretreated with different concentrations $(12.5,25,50 \mu \mathrm{g} / \mathrm{mL})$ of isoeugenin for $1 \mathrm{~h}$ followed by LPS $(1 \mu \mathrm{g} / \mathrm{mL})$ for $24 \mathrm{~h}$. NOR values were obtained in the absence of LPS and samples. The experiment was repeated three times and similar results were obtained. Values represent means \pm S.D. of three independent experiments. ${ }^{\# \#} p<0.01$,

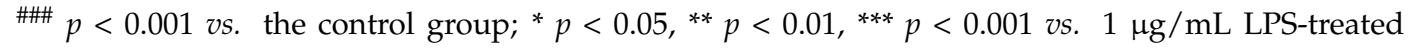
group; significant differences between treated groups were determined using ANOVA and Dunnett's post hoc test.

\section{Experimental Section}

\subsection{General Information}

Chromatographic isolation was performed on the open columns using normal or reverse stationary phases. Spectra of the isolated compounds were measured using a NMR spectrometer (Bruker Co., Rheinstetten, Germany). A quantitative analysis was performed on the HPLC system (Varian Co., Palo Alto, CA, USA) consisting of two Prostar 210 pumps, a Prostar 325 UV-vis detector and a Shiseido Capcell PAK C18 column ( $5 \mu \mathrm{m}, 4.6 \mathrm{~mm} \times 250 \mathrm{~mm}$, Japan). Dulbecco's modified Eagle's minimum essential medium (DMEM), fetal bovine serum (FBS), penicillin, and streptomycin were obtained from Life Technologies Inc. (Grand Island, NY, USA). iNOS, COX-2, and $\beta$-actin monoclonal antibodies and the peroxidase-conjugated secondary antibody were purchased from Santa Cruz Biotechnology, Inc. (Santa Cruz, CA, USA).

\subsection{Plant Material}

The rhizome of I. cylindrica was purchased from the Chun-Il medicinal herb store in Wonju City, Korea. This medicinal herb was identified by Prof. Byong-Min Song (Department of Forestry Science, Sangji University, Wonju City, Korea). The voucher specimen (natchem \#68) was deposited in the laboratory of Natural Product Chemistry, Department of Pharmaceutical Engineering, Sangji University.

\subsection{Extraction and Fractionation}

The plant material (3 kg) consisting of the rhizome of I. cylindrica was extracted with $\mathrm{MeOH}(4 \mathrm{~L})$ under reflux for $5 \mathrm{~h}$ and repeated three times. The extracted solution was filtered and evaporated under reduced pressure to give a $\mathrm{MeOH}$ extract $\left(501.7 \mathrm{~g}\right.$ ). This extract was suspended in $\mathrm{H}_{2} \mathrm{O}$ and fractionated in a separating funnel with hexane $(0.8 \mathrm{~L})$ three times. The hexane-soluble portion was concentrated to dryness in vacuo to give a hexane fraction ( $24.40 \mathrm{~g})$. Similarly, the remaining $\mathrm{H}_{2} \mathrm{O}$ layer was further successively fractionated with $\mathrm{CHCl}_{3}, \mathrm{EtOAc}$, and $\mathrm{BuOH}$, and then concentrated. The yields of the $\mathrm{CHCl}_{3}$, EtOAc, and $\mathrm{BuOH}$ fractions were $14.56 \mathrm{~g}, 12.58 \mathrm{~g}$, and $136.1 \mathrm{~g}$, respectively. The concentration of the final aqueous phase gave an $\mathrm{H}_{2} \mathrm{O}$ fraction $(348.8 \mathrm{~g})$. 


\subsection{Isolation of the Componds}

The $\mathrm{CHCl}_{3}$ fraction $(10 \mathrm{~g})$ was chromatographed on a silica gel column $(280 \mathrm{~g}, 5 \mathrm{~cm} \times 35 \mathrm{~cm})$ using $\mathrm{CHCl}_{3}-\mathrm{MeOH}-\mathrm{H}_{2} \mathrm{O}$ (10:2:2, lower layer). Forty-five fractions (fr.4-fr.5; $60 \mathrm{~mL}$ (each)) were then grouped into 10 subfractions (Gr.1-Gr.10) according to their band profiles in TLC.

To obtain the main component from Gr.2, silica gel $(55 \mathrm{~g}, 3 \mathrm{~cm} \times 30 \mathrm{~cm})$ column chromatography was performed using $\mathrm{CHCl}_{3}-\mathrm{MeOH}-\mathrm{H}_{2} \mathrm{O}$ (10:2:2, lower layer) to yield compound 1. Further, to obtain the main component from Gr.6, silica gel $(60 \mathrm{~g}, 3 \mathrm{~cm} \times 30 \mathrm{~cm})$ column chromatography was undertaken using $\mathrm{CHCl}_{3}-\mathrm{MeOH}-\mathrm{H}_{2} \mathrm{O}$ (10:2:1, lower layer) to yield compound 2. To obtain the main component from Gr.8, it was chromatographed on silica gel $(55 \mathrm{~g}, 3 \mathrm{~cm} \times 30 \mathrm{~cm}$ ) with the solvent $\mathrm{CHCl}_{3}-\mathrm{MeOH}-\mathrm{H}_{2} \mathrm{O}$ (10:2.2:1, lower layer) to yield compound 4.

Compounds 2, 3, and 4 were identified as ferulic acid, p-coumaric acid, and caffeic acid, respectively, by analysis of their corresponding ${ }^{1} \mathrm{H}$ - and ${ }^{13} \mathrm{C}-\mathrm{NMR}$ spectra. The three compounds 2-4 were the same as standards of each compound by TLC and HPLC. The retention times of p-coumaric acid, ferulic acid and caffeic acid were $10.30 \mathrm{~min}, 11.75 \mathrm{~min}$, and $6.92 \mathrm{~min}$, respectively, on the HPLC chromatogram. On the other hand, compound 1 with a retention time of $21.42 \mathrm{~min}$ on the HPLC chromatogram was structurally determined to be isoeugenin through the interpretation of 2D-NMR spectra including ${ }^{1} \mathrm{H}-{ }^{1} \mathrm{H}$ correlation spectroscopy (COSY), ${ }^{1} \mathrm{H}_{-}-{ }^{13} \mathrm{C}$ COSY, $\mathrm{HMBC}$, and nuclear Overhauser effect spectroscopy NMR spectra.

7-Hydroxy-5-methoxy-2-methylchromone (isoeugenin, 1): Yellow gum; UV $\lambda_{\max } \mathrm{MeOH} \mathrm{nm}(\log \varepsilon$ ): 209 (4.22), 307 (3.87); ${ }^{1} \mathrm{H}-\mathrm{NMR}$ (600 MHz, dimethyl sulfoxide (DMSO- $\left.d_{6}\right): 6.59(1 \mathrm{H}, \mathrm{d}, J=1.8 \mathrm{~Hz}, \mathrm{H}-8)$, $6.55(1 \mathrm{H}, \mathrm{d}, J=1.8 \mathrm{~Hz}, \mathrm{H}-6), 5.60(1 \mathrm{H}, \mathrm{s}, \mathrm{H}-3), 3.93\left(1 \mathrm{H}, \mathrm{s}, \mathrm{OCH}_{3}\right), 2.52\left(3 \mathrm{H}, \mathrm{s}, 2-\mathrm{CH}_{3}\right) ;{ }^{13} \mathrm{C}-\mathrm{NMR}$ (150 MHz, DMSO-d $d_{6}$ ): 138.7 (C-2), 87.2 (C-3), 169.9 (C-4), 162.2 (C-5), 101.0 (C-6), 160.9 (C-7), 116.5 (C-8), $156.6(\mathrm{C}-9), 106.6(\mathrm{C}-10), 57.0\left(\mathrm{OCH}_{3}\right), 23.5\left(\mathrm{CH}_{3}\right)$; High-resolution electrospray ionization mass spectrometry (HR-ESI-MS) $m / z$ (rel. int.): 206.0605 (100, $\left.\mathrm{C}_{11} \mathrm{H}_{10} \mathrm{O}_{4}\right)$.

Ferulic Acid (2): Colorless gum; EI-MS (70 eV): m/z $194.1\left(\mathrm{M}^{+}\right) ;{ }^{1} \mathrm{H}-\mathrm{NMR}\left(500 \mathrm{MHz}, \mathrm{CD}_{3} \mathrm{OD}\right)$ and ${ }^{13} \mathrm{C}-\mathrm{NMR}\left(125.5 \mathrm{MHz}, \mathrm{CD}_{3} \mathrm{OD}\right) \delta:$ [13].

p-Coumaric Acid (3): Colorless needles; m.p. $210-213{ }^{\circ} \mathrm{C}$; EI-MS (70 eV): $m / z 164.1\left(\mathrm{M}^{+}\right),{ }^{1} \mathrm{H}-\mathrm{NMR}$ (500 MHz, CD 3 OD) and ${ }^{13} \mathrm{C}-\mathrm{NMR}\left(125.5 \mathrm{MHz}, \mathrm{CD}_{3} \mathrm{OD}\right)$ : [14].

Caffeic Acid (4): Yellow powder, m.p. $223-225^{\circ} \mathrm{C}$ (dec.); EI-MS (70 eV): $m / z$ 180.1 (M+), 163.06, 135.08; ${ }^{1} \mathrm{H}-\mathrm{NMR}\left(500 \mathrm{MHz}, \mathrm{CD}_{3} \mathrm{OD}\right)$ and ${ }^{13} \mathrm{C}-\mathrm{NMR}\left(125.5 \mathrm{MHz}, \mathrm{CD}_{3} \mathrm{OD}\right)$ [15].

\subsection{HPLC Analysis}

The HPLC system used for the present study consists of a Varian Prostar 210 solvent delivery module (Agilent Technologies, Santa Clara, CA, USA), Prostar 325 UV-Vis detector, and 20- $\mu \mathrm{L}$ sample loop. A Shiseido Capcell Pak C18 HPLC column ( $5 \mu \mathrm{m}, 250 \mathrm{~mm} \times 4.6 \mathrm{~mm}$, Tokyo, Japan) was used. The two solvents used for gradient elution were solvent A $0.5 \%$ HOAc aqueous solution, and solvent B $0.5 \%$ HOAc-MeOH solution. Regression equations were established as shown in Table 1, by estimating peak areas measured at six concentrations $(12,5,25,50,100,200$, and $1000 \mu \mathrm{g} / \mathrm{mL})$. Each equation was verified for linearity at $R^{2}>0.999$. Detection was performed at the fixed wavelength of $254 \mathrm{~nm}$.

\subsection{Preparation of Standard and Test Solutions}

The four compounds, isoeugenin, ferulic acid, p-coumaric acid, and caffeic acid, which were isolated from I. cylindrica were used for preparation of standard solutions. Stock solutions (each $1000 \mu \mathrm{g} / \mathrm{mL}$ ) that were made by dissolving each standard compound in $\mathrm{MeOH}$ were further diluted to produce working standard solutions. The rhizome of I. cylindrica was pulverized, added to $20 \mathrm{~mL} \mathrm{MeOH}$, and then extracted at $60^{\circ} \mathrm{C}$ for $6 \mathrm{~h}$ using an ultrasonicator. The extracted solution was 
filtered through a syringe filter and used for sample solution. The other four sample solutions (each $1000 \mu \mathrm{g} / \mathrm{mL}$ ) were prepared by dissolving hexane $\mathrm{CHCl}_{3}$, $\mathrm{EtOAc}$, and $\mathrm{BuOH}$ fractions in $\mathrm{MeOH}$.

\subsection{Cell Culture and Sample Treatment}

The RAW264.7 murine macrophage cell line was obtained from the Korea Cell Line Bank (Seoul, Korea). These cells were grown at $37{ }^{\circ} \mathrm{C}$ in Dulbecco's modified Eagle's medium containing $10 \%$ fetal bovine serum, $100 \mathrm{U} / \mathrm{mL}$ penicillin, and $100 \mu \mathrm{g} / \mathrm{mL}$ streptomycin in a humidified atmosphere of $5 \% \mathrm{CO}_{2}$. Cells were incubated with various concentrations of the $\mathrm{MeOH}$ extract, fractions, or with positive controls (L-N6-(1-iminoethyl)lysine (NIL)), and then stimulated with LPS (1 mg/mL) for the indicated time. Various concentrations of the $\mathrm{MeOH}$ extract, four fractions, and isolated compounds dissolved in DMSO were added to the medium.

\subsection{Measurement of Cell Viability by 3-(4,5-Dimethylthiazol-2-yl)-2,5-diphenyltetrazolium Bromide (MTT) Assay}

Cells were incubated after being treated with various concentrations of four compounds for $24 \mathrm{~h}$. This medium was further incubated for $4 \mathrm{~h}$ after adding $5 \mathrm{mg} / \mathrm{mL}$ MTT solution. After discarding the medium, the formazan crystals formed was dissolved in DMSO and then the absorbance measured at $570 \mathrm{~nm}$ using an Epoch microplate spectrometer (Biotek, Winooski, VT, USA).

\subsection{Measurement of Nitrite in Culture Media}

The concentration of NO produced in RAW264.7 cells was determined by measuring nitrite $\left(\mathrm{NO}_{2}{ }^{-}\right)$levels in the medium using Griess reagent (1\% sulfanilamide in 5\% phosphoric acid, $1 \%$ $\alpha$-naphthylamide in $\mathrm{H}_{2} \mathrm{O}$ ) as previous study [20]. After incubating the medium with the supernatant $(50 \mu \mathrm{L})$ and Griess reagent $(50 \mu \mathrm{L})$ for $15 \mathrm{~min}$, the absorbance was measured at $540 \mathrm{~nm}$ with a microplate reader.

\subsection{Western Blot Analysis}

The cells were re-suspended in a commercial lysis buffer (PRO-PREPTM, Intron Biotechnology, Seoul, Korea) and incubated for $20 \mathrm{~min}$ at $4{ }^{\circ} \mathrm{C}$. Cell debris was removed by micro-centrifugation, followed by quick freezing of the supernatants. The protein concentration was determined using the Bio-Rad protein assay reagent according to the manufacturer's instructions (Bio-Rad, Hercules, CA, USA). Aliquots of each protein sample $(30 \mu \mathrm{g})$ were separated on a sodium dodecyl sulfate (SDS) polyacrylamide gel and transferred onto a polyvinylidene fluoride (PVDF) membrane. Membranes were incubated for $1 \mathrm{~h}$ with $5 \%$ skim milk at room temperature, followed by incubation overnight with a primary antibody (iNOS, COX-2 (Santa Cruz Biotechnology)) at $4{ }^{\circ} \mathrm{C}$. Blots were washed three times with Tween 20/Tris-buffered saline (T/TBS) and incubated with a 1:1000 dilution of horseradish peroxidase-conjugated secondary antibody (Jackson Immunoresearch, Inc., Baltmore, MD, USA) for $2 \mathrm{~h}$ at room temperature. Blots were again washed three times with T/TBS, and then developed by enhanced chemiluminescence (GE Healthcare, Milwaukee, WI, USA).

\subsection{Quantitative Real-Time PCR Analysis}

Total RNA was isolated from the cells or liver tissue using a Trizol reagent (Invitrogen, Carlsbad, CA, USA). cDNA was obtained using isolated total RNA $(2 \mu \mathrm{g}), \mathrm{d}(\mathrm{T}) 16$ primer and AMV reverse transcriptase. Relative gene expression was quantified by use quantitative real-time PCR (Real Time PCR System 7500, Applied Biosystems, Foster, CA, USA) with SYBR Primix Ex Taq. The The oligonucleotide primers used in this study are listed below and were purchased from Bioneer (Seoul, Korea): for TNF- $\alpha$ were ATGAGCACAGAAAGCATGAT (forward) and TACAGGCTTGTCACTCG AAT (reverse); for IL-6 were TTCCATCCAGTTGCCTTCTTG (forward) and GGGAGTGGTATCC TCTGTGAAGTC (reverse); for IL-1 $\beta$ were GATCCACACTCTCCAGCTGCA (forward) and CAAC CAACAAGTGATATTCTCCATG (reverse); for GAPDH GACGGCCGCATCTTCTTGT(forward) and 
CACACCGACCTTCACCATTTT (reverse:), and the suitable size of synthesized cDNA was $200 \mathrm{bp}$. The results are expressed as the ratio of optimal density to GAPDH.

\section{Conclusions}

In the present study, we obtained four compounds from a $\mathrm{MeOH}$ extract of I. cylindrica rhizomes and tested them for anti-inflammatory activity. As part of our study, we identified the novel compound isoeugenin for the first time and also we demonstrated the anti-inflammatory effects of isoeugenin on LPS-activated RAW264.7 macrophages. Based on these findings, isoeugenin could be a useful pharmacologic tool for improving our understanding of basic cellular functions and suggest that isoeugenin be considered for evaluation as a potential treatment option for inflammatory diseases.

Acknowledgements: This work (Grants No. 2014C24410) was supported by Business for Cooperative R \& D between Industry, Academy, and Research Institute funded Korea Small and Medium Business Administration in 20 .

Author Contributions: Hyo-Jin An, Agung Nugroho, Hee-Juhn Park came up with the conception of this experiment. Hyo-Jin An and Hee-Juhn Park wrote the manuscript. Agung Nugroho and Byung-Min Song carried out the experiments and analyzed the spectral data. All authors had read and approved the final manuscript.

Conflicts of Interest: The authors declare no conflict of interest.

\section{References}

1. Kim, B.K.; Lim, J.S.; Kil, K.J. Effects of Imperatae Rhizoma Extract on T helper 2 cell differentiation. Korean J. Herbol. 2014, 29, 27-33. [CrossRef]

2. Yoon, J.S.; Lee, M.K.; Sung, S.H.; Kim, Y.C. Neuroprotective 2-(2-phenylethyl)chromones of Imperata cylindrica. J. Nat. Prod. 2006, 69, 290-291. [CrossRef] [PubMed]

3. Lee, D.Y.; Han, K.M.; Song, M.C.; Lee, D.G.; Rho, Y.D.; Baek, N.I. A new lignan glycoside from the rhizomes of Imperata cylindrica. J. Asian Nat. Prod. Res. 2008, 10, 337-341. [CrossRef] [PubMed]

4. Matsunaga, K.; Ikeda, M.; Shibuya, M.; Ohizumi, Y. Cylindol A, a novel biphenyl ether with 5-lipoxygenase inhibitory activity, and a related compound from Imperata Cylindrica. J. Nat. Prod. 1994, 57, 1290-1293. [CrossRef] [PubMed]

5. Matsunaga, K.; Shibuya, M.; Ohizumi, Y. Cylindrene, a novel sesquiterpenoid from Imperata cylindrica with inhibitory activity on contractions of vascular smooth muscle. J. Nat. Prod. 1994, 57, 1183-1184. [CrossRef] [PubMed]

6. Liu, X.; Zhang, B.F.; Yang, L.; Chou, G.X.; Wang, Z.T. Four new compounds from Imperata cylindrica. J. Nat. Med. 2014, 68, 295-301. [CrossRef] [PubMed]

7. Cerdeira, A.L.; Cantrell, C.L.; Dayan, F.E.; Byrd, J.D. Tabanone, a new phytotoxic constituent of Cogongrass (Imperata cylindrica). Weed Sci. 2012, 60, 212-218. [CrossRef]

8. Kanwar, J.R.; Kanwar, R.K.; Burrow, H.; Baratchi, S. Recent advances on the roles of NO in cancer and chronic inflammatory disorders. Cur. Med. Chem. 2009, 16, 2373-2394. [CrossRef]

9. An, H.J.; Kim, I.T.; Park, H.J.; Kim, H.M.; Choi, J.H.; Lee, K.T. Tormentic acid, a triterpenoid saponin, isolated from Rosa rugosa, inhibited LPS-induced iNOS, COX-2, and TNF-alpha expression through inactivation of the nuclear factor-kappab pathway in RAW264.7 macrophages. Int. Immunopharmacol. 2011, 11, 504-510. [CrossRef] [PubMed]

10. Vuolteenaho, K.; Moilanen, T.; Knowles, R.G.; Moilanen, E. The role of nitric oxide in osteoarthritis. Scand. J. Rheumatol. 2007, 36, 247-258. [CrossRef] [PubMed]

11. Tsui, W.G.; Brown, G.D. Chromones and chromaones from Baeckea frutescens. Phytochemistry 1996, 43, 871-876. [CrossRef]

12. Hauser, D.; Zardin, T. Isolation of 6-hydroxymethyl-eugenin from Chaetomium minutum. Experientia 1972, 28, 1114. [CrossRef]

13. Park, H.J.; Young, H.S.; Kim, J.O.; Rhee, S.H.; Choi, J.S. A Study on the Chemical Constituents of Orostachys japonicus A. Berger. Korean J. Pharmacogn. 1992, 22, 78-84. 
14. Yi, B.; Hu, L.; Mei, W.; Zhou, K.; Wang, H.; Luo, Y.; Wei, X.; Dai, H. Antioxidant phenolic compounds of cassava (Manihot esculenta) from Hainan. Molecules 2011, 16, 10157-10167. [CrossRef] [PubMed]

15. Bhatt, B. Chemical constituents of Solanum xanthocarpum. J. Chem. Pharm. Res. 2011, 3, 176-181.

16. Aggarwal, B.B.; Natarajan, K. Tumor necrosis factors: Developments during the last decade. Eur. Cytokine Netw. 1996, 7, 93-124. [PubMed]

17. Kaplanski, G.; Marin, V.; Montero-Julian, F.; Mantovani, A.; Farnarier, C. IL-6: A regulator of the transition from neutrophil to monocyte recruitment during inflammation. Trends Immunol. 2003, 24, 25-29. [CrossRef]

18. Connell, L.; McInnes, I.B. New cytokine targets in inflammatory rheumatic diseases. Best Pract. Res. Clin. Rheumatol. 2006, 20, 865-878. [CrossRef] [PubMed]

19. Dinarello, C.A. Interleukin-1 beta, interleukin-18, and the interleukin-1 beta converting enzyme. Ann. N. Y. Acad. Sci. 1998, 856, 1-11. [CrossRef] [PubMed]

20. Cheon, S.Y.; Chung, K.S.; Jeon, E.; Nugroho, A.; Park, H.J.; An, H.J. Anti-inflammatory Activity of Saxifragin via Inhibition of NF-kB Involves Caspase-1 Activation. J. Nat. Prod. 2015, 78, 1579-1585. [CrossRef] [PubMed]

Sample Availability: Samples of the isoeugenin, ferulic acid, coumaric acid, caffeic acid are available from Hee-Juhn Park.

(C) 2015 by the authors; licensee MDPI, Basel, Switzerland. This article is an open access article distributed under the terms and conditions of the Creative Commons by Attribution (CC-BY) license (http:/ / creativecommons.org/licenses/by/4.0/). 